\title{
Salon
}

\section{Talking over patients: sTOP}

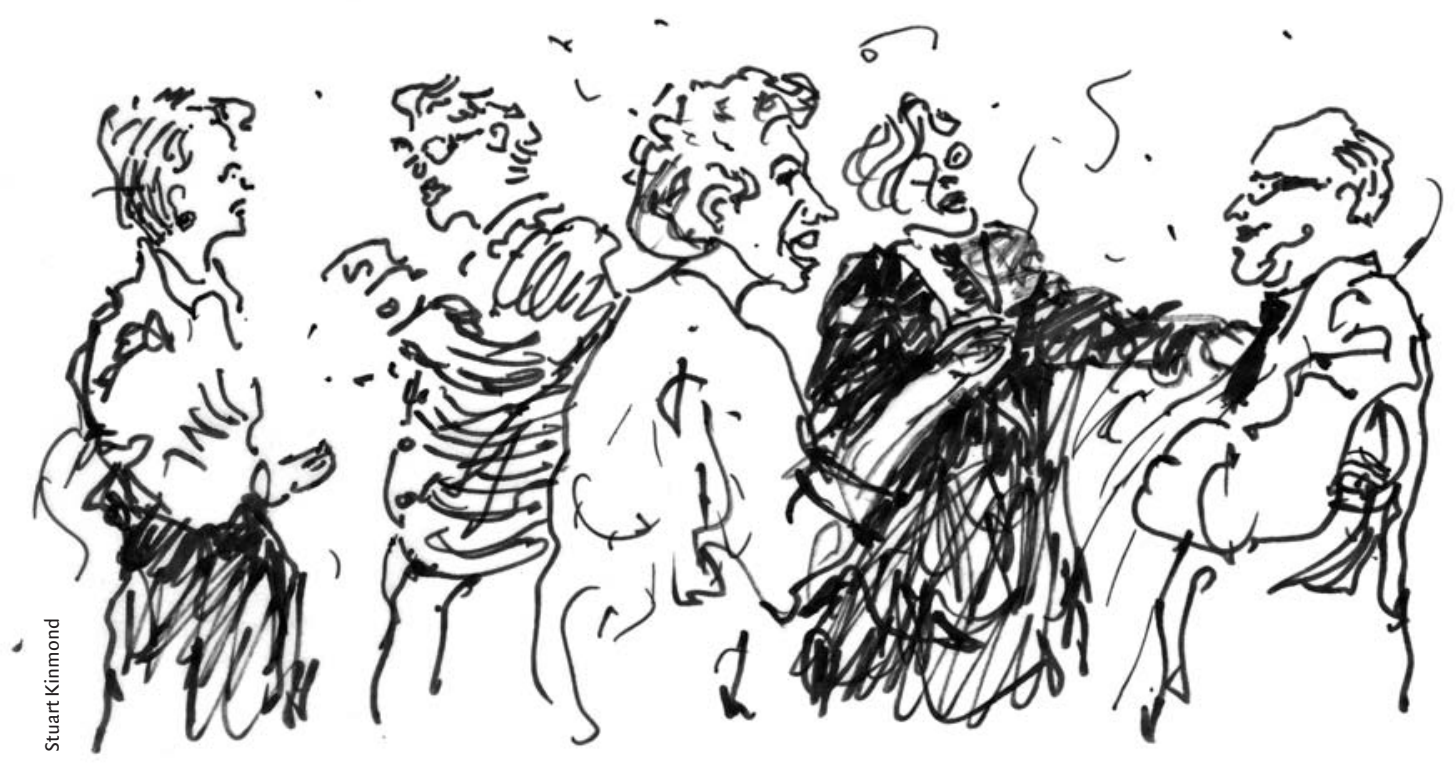

A n old woman lies quietly on a scanning table; the detector buzzes back and forth looking for metastases. Two technicians stand where the woman cannot see them; they are audibly discussing the "big date" from last weekend. A doctor emerges from an occupied examination room into a full patient waiting area. He spots his colleague at the other side of the area; he exclaims, for all to hear, how much he appreciated the colleagues recent lecture on multidrug resistant tuberculosis. Up on the ward, an orderly stands at the nursing station, as patients come and go, and ventilates to the ward coordinator about her long hours, low salary and low back pain. The only thing that is not wrong with any one of these spectacles is that similar ones are an every day, increasingly prevalent, occurrence.

What is wrong with this type of behaviour is that it is rude, unethical and hurtful. It is rude to those who overhear, as if one's parents had not already inculcated this into us, because they have no way to avoid it and because they have placed themselves into the circumstance for a different purpose.

Talking over patients is unethical. It should not need spelling out as to why but, given the prevalence of this type of talk, it must be necessary. Such talk violates the first principle of clinical ethics: the autonomy principle. This principle, usually deployed to protect the right of the person to decide for oneself, is based on respect for the person. Emmanuel Kant argued that autonomy flows from the recognition that all persons have unconditional worth. Talking over patients implies that the presence of the other is of no consequence.

Finally, as if the foregoing were not sufficiently compelling to stop talking over patients, we should note that it is also hurtful. Most patients are anxious; some are afraid of having a fatal disease; and still others, with a fatal disease, of dying. They are feeling very dependent on others. Off-the-cuff remarks can be taken in a way that no one would intend. Different from inescapable overhearing that everyone can recognize as unwanted (see CMAJ I998;158:613-4), these instances show that the speaker is oblivious of the other.
Good parents don't demean their children by talking over them. Good lovers spare the non-participating public their intimacies. How about medical professionals? Since we can not overcome an evil we have not even named, I will propose one: TOP Talk. Let me be clear: TOP Talk is an unprofessional behaviour not because the topic of conversation is bad, but because the circumstance is an unacceptable time and place for it.

Clinical directors should discuss this problem of TOP Talk with their staff. There should be a campaign to educate and to eradicate. Why, I even have a poster device to propose for the campaign — "sTOP" — stop talking over patients!

\section{Ken Flegel MDCM MSc}

Senior Associate Editor CMAJ

Have you got an opinion about this article? Post your views at www.cmaj.ca. Potential Salon contributors are welcome to send a query to salon@cma.ca. 